\title{
THE ASSESSMENT OF RISK FACTORS FOR WORK SAFETY AT THE WORKPLACE FOR DRIVER
}

\author{
Beatrice Daniela TUDOR \\ "Dunarea de Jos" University of Galati, Romania \\ e-mail: btudor@ugal.ro
}

\begin{abstract}
In this is paper present the calculation of the overall risk level for workplace driver. Risk assessment is the first step towards safer and healthier jobs, and it is the way to reduce accidents at work and occupational diseases. The new trends in managing an organization are to consider as performing an organization that is equally concerned with improving the quality of products / services and increasing economic efficiency, as well as providing adequate working conditions for employees and environmental protection environment, by increasing the quality of life in general. All of these components are addressed within integrated management systems, which usually aim to organize the operation of companies. Employee health and safety, protection of neighbouring populations, flora and fauna, water and soil are just as important as the organization's profit. But what does the health and safety component of work in this integrated system involve? The increase in profit results from the reduction of material losses due to accidents and damages, the reduction of absenteeism due to medical leave, the elimination of losses caused by penalties resulting from non-compliance with legal requirements, etc.
\end{abstract}

KEYWORDS: risk factors, work process, risk level, safety

\section{Introduction}

The optimization of the activity of prevention of accidents at work and occupational diseases in a system, is the risk assessment of the respective system.

Risk assessment involves identifying all the risk factors, from the analysed system, and quantifying their size, based on the combination, between two parameters: the severity and frequency of the maximum possible consequence, on the human body. Thus, partial risk levels are obtained, for each risk factor, respectively global risk levels, for the entire system analysed $[1,5]$.

The method developed by I.N.C.D.P.M. Bucharest, is part of the analytical, semi-quantitative methods category, and consists, in identifying all the risk factors, in the analysed system, (workplace), with the help of predetermined checklists, and quantifying the size of the risk, for each risk factor in part, based on the combination, between the severity, and the frequency of the maximum foreseeable consequence. The overall risk level, at the workplace, is determined, as a weighted average, of the partial risk levels, so that the compensations are minimal. The level of security results indirectly, being inversely proportional to the level of risk [2].

The application of the method is finalized with two centralizing documents, for each job: the risk assessment sheet, and the proposed measures sheet.

\section{Theoretical considerations and method of research}

\subsection{Work process}

The work process consists in carrying out transports of various goods both on national and international routes in accordance with legal requirements to the beneficiaries, as well as carrying out the current maintenance of the means of transport (oil change, antifreeze, brake fluid additions, wheels, tire running, car wash, etc.).

Components of the assessed work system

\subsection{Work equipment}

Means of transport: heavy goods vehicles for international transport; toolbox; spare tire; reflective 
triangle; medical kit; jack; fire extinguisher; shovel (in winter); rubber chains (in winter); maintenance materials (oil, antifreeze, refill brake fluid, fuses, bulbs, etc.); various merchandise.

\subsection{Work task}

In order to accomplish the workload, the driver performs mainly the following activities:

- before leaving the race, the company will be presented in a good health condition, resting, prepared for the transport; assist in cargo loading; does not load the vehicle over the transportation capacity; carries out the transport in accordance with the contractual provisions and the instructions received; is responsible for the observance of the health and safety measures of labour and the US provided by the legislation in force, namely: personal documents (auto license, driver attestation, identity card, medical insurance); documents for the vehicle (registration certificate, beaver, technical inspection, tachograph, etc.); prepares supplies with spare parts, materials, tires, fuel; immediately communicate to the transport coordinator any traffic event in which he or the vehicle is involved; upon arrival from the race, hand over all the documents of the race received on departure and those obtained in the course of the course to justify its activity and the vehicle throughout the race; has the obligation to sign at the arrival of the race any reported malfunction or any abnormal operation of any faction; has the obligation, on arrival from the race, to provide details about the technical condition of the truck, the need for spare parts or other operations which it considers necessary for the optimum operation of the truck; assist in making repairs; permanently takes the necessary measures in the optimal conditions of transportation depending on the atmospheric conditions; it is forbidden to comply with any provision made by the transport beneficiary which would lead to the circumvention of the law or the commission of offenses; has the obligation to answer the phone by providing full details of the situations for which it is called; permanently monitors the validity of documents; respects the driver's work and rest regime provided by the legislation in force; it is forbidden for the employee to claim and receive money, gifts or other advantages to act against his obligations.

This is true even when, by receiving undue benefits, society has not been directly damaged; the obligation to observe the provisions of the internal regulations, as well as in the individual labour contract; maintain order and cleanliness at work; not to drink alcohol or to facilitate the practice of doing these things at the workplace; executes according to the requirements, available to the administrator and other stipulated provisions; is responsible for compliance with the road code; is responsible for the maintenance in service of the truck entrusted; announces the administrator in the event of a malfunction of the truck entrusted when he is in the race; participates in regular work safety training and emergency situations; perform regular medical checkups specific to the job; carry on the routes and routes indicated, eliminating unjustified interruptions; do not run without the tachograph being in operation.

\subsection{The work environment}

The elements that define the work environment of the performer (driver) are:

- low air temperature in the cool season in the event of air conditioning failure; high air temperature in the warm season for the heating system; airflows in some working areas, due to ventilation, leakage in the cabin, open windows on both sides of the cabin; noise level - discontinuous (below the maximum allowable); low light level at work at night - example when driving at night, is the phenomenon of blindness caused by the incorrect use of lights by other road users; natural calamities - surprise, earthquake; weather - wind surprise, blizzard ground breaks, tree crashes, landslides; pneumoconiogeni powders present in the outer atmosphere of the workplace - example driving the dust by selling etc.

\section{Identified risk factors}

\subsection{Work equipment}

Mechanical risk factors:

- moving machine organs: gripping, entrainment of the hand or clothing by transmissions (water pump) or by mechanical transmissions (planetary, cardan) when making interventions on the car; road traffic accident when driving on public roads (hitting the means of transport); hitting the cars when traveling through the beneficiary premises, through the premises of the supplying company, as well as traveling from home to the workplace and vice versa; automatic locking of the steering mechanism or the brake system on the road, as well as stopping the engine operation while the truck is moving, failure of the hydraulic safety system; displacements of trucks under the effect of gravity, due to their non-assurance during stationary (stationary without the introduction of the gearshift lever in a gear and without pulling the handbrake); slipping, rolling or toppling of stored materials without ensuring stability in the receiving company's premises, as well as slipping, rolling, overturning or collapsing materials in the vehicle bin; the free fall of parts to work under the truck in case of interventions; dropping the truck on the jack, the 
press on changing the wheels or during the interventions under the car, the fall of the shuttle from the truck bay to its descending or lifting; dropping the truck from the truck to its normal position, during engine operation, electrical installation, etc., due to the fact that it is not fitted with devices provided for this purpose; knocking with hand tools; liquid oil, fuel, brake fluid leakage; deviation from the normal carriage trajectory (tread depth, trench holes, runway obstacles, tire burst, avoidance of an obstacle, car, pedestrian, etc.) - danger of overturning the car while driving; the design of particles on the windscreen when broken; antifreeze rupture when pressure hoses are broken; airborne rupture at hose breakage to ensure inflation of the tire, including the possibility of hitting the hose connection at the air compressor; contact with dangerous surfaces or contours (bumpy, bumpy, slippery, abrasive etc.) - example when performing maintenance and maintenance operations; pressure vessels - example: fire extinguisher from the machine - explosion hazard; vibrations in the car's cab, caused by inadequate engine operation, running track irregularities, defective damping systems, etc.

\section{Thermal risk factors:}

- high temperature of surfaces, accidentally touched by inspections or repairs; lowered temperature of metallic surfaces in cold weather; flame, flame - example: short circuit at the car's electrical system - fire hazard.

\section{Electric risk factors:}

- Direct and indirect touching by electric shock and through the emergence of step voltage possibilities that can occur to the beneficiaries, to the suppliers of materials, when traveling on public roads (road drops of some air conductors that ensure the transport of electricity).

\section{Chemical risk factors:}

- working with toxic substances - antifreeze, brake fluid; working with caustic substances electrolyte batteries - chemical burns; work with or in the vicinity of flammable substances (fuels, oils, greases).

\subsection{Work environment}

\section{Physical risk factors:}

- low air temperature in the cool season in the event of air conditioning failure; high air temperature in the warm season for the heating system; airflows in some working areas, due to ventilation, leakage in the cabin, open windows on both sides of the cabin; noise level - discontinuous (below the maximum allowable); low light level at work at night - example when driving at night, is the phenomenon of blindness caused by the incorrect use of lights by other road users; natural calamities - earthquake; weather - wind surprise, blizzard ground breaks, tree crashes, landslides; pneumoconiogenic powders present in the outer atmosphere of the workplace example driving the dust by selling etc.

\section{Chemical risk factors:}

- toxic gases - example: exhaust gas from the truck - possibility to accumulate in the truck cabin; working in the area with potential fire or explosion hazard - example: within the fuelling stations where the fuel is being fed.

\section{Work task:}

Inappropriate content of workload relative to security requirements:

- admission of workers to work, under inappropriate psychological and physiological conditions; tolerance of deviations from work discipline, from observing the rules of work safety; the use as a working method of the open flame to start the engine; the assignment of the driver in order to carry out work tasks with incomplete work in the field of safety and health at work; omissions or errors in the preconditioning of work operations - example: disposition of activities for a driver who does not have the proper qualification for the activity to be carried out, etc.

\section{Physical request:}

- dynamic effort in manual handling of masses; forced or vicious jobs - job position predominantly "sitting"; high working pace on some days of service; permanent attention to truck driving on public roads (especially when traveling at night); difficult decisions taken shortly in some situations when driving on public roads; performing short and medium cycle operations; psychological stress related to the danger of a traffic accident when traveling with the means of public transport on public roads, psychological stress related to the danger of being assaulted by unknown persons during the performance of their duties.

\subsection{Executor}

The wrong actions:

- performing unpredictable operations in the work task or in a different manner than the technical working provisions; execution of manoeuvres not permitted by the legislation (road code) governing the circulation on national and international public roads or technological provisions during the stationary work; not to carry out statutory breaks at the intervals stipulated by the legislation in force, in the case of long-distance journeys; car interventions without 
stopping the engine; the introduction of the upper limbs in the belt area through the belt or in the area of the mechanical transmission when the engine is in running order; the use of an inappropriate technical machine or the periodic checking period, exceeded; the use of inappropriate manual tools during the works; exceeding the maximum number of people admitted in the cab or the maximum permissible load that can be carried by truck; lowering the slopes with the gear lever in the "neutral" position; carrying out the towing operation with supplied means or connecting the trailer with improvised means; inappropriate positioning of the car when performing interventions at or under the car, when changing wheels - example: use of jacks, defective presses, non-use of wheel feathers, non-introduction of the gearshift lever in a gear, non-assurance with handbrake etc.; non-uniform loading of the materials in the bin of the car - danger of overturning while traveling on public roads; loading the car with a mass greater than the maximum authorized weight; inflating tires with higher pressures or using them at lower pressures than the technical book; performing operations on the engine without securing the cab against the closure with the device provided for this purpose; failure to secure the shuttle from the car's bay during its loading / unloading - accidental fall; non-synchronization to teamwork - example: with workers from the trade companies that insure the repair or repair of the car, the workers who load / unload the truck, etc .; displacements, stationary in dangerous areas; falling to the same level: by unbalance, slippage, obstruction; falling from a height: through a hollow, unbalanced, sliding; accidental communications; lightening cigarette lighter in the fuel supply station; at work under the influence of alcohol, in fatigue, under the influence of drugs, etc.;

\section{Omissions:}

- omission of performing operations that ensure its own security; misapplication or misuse of E.I.P. and other means of protection.

The overall level of risk in the workplace is:

- organizing the work so as to reduce the noise by limiting the duration and intensity of the exposure and establishing sufficient breaks, during the work program.

8

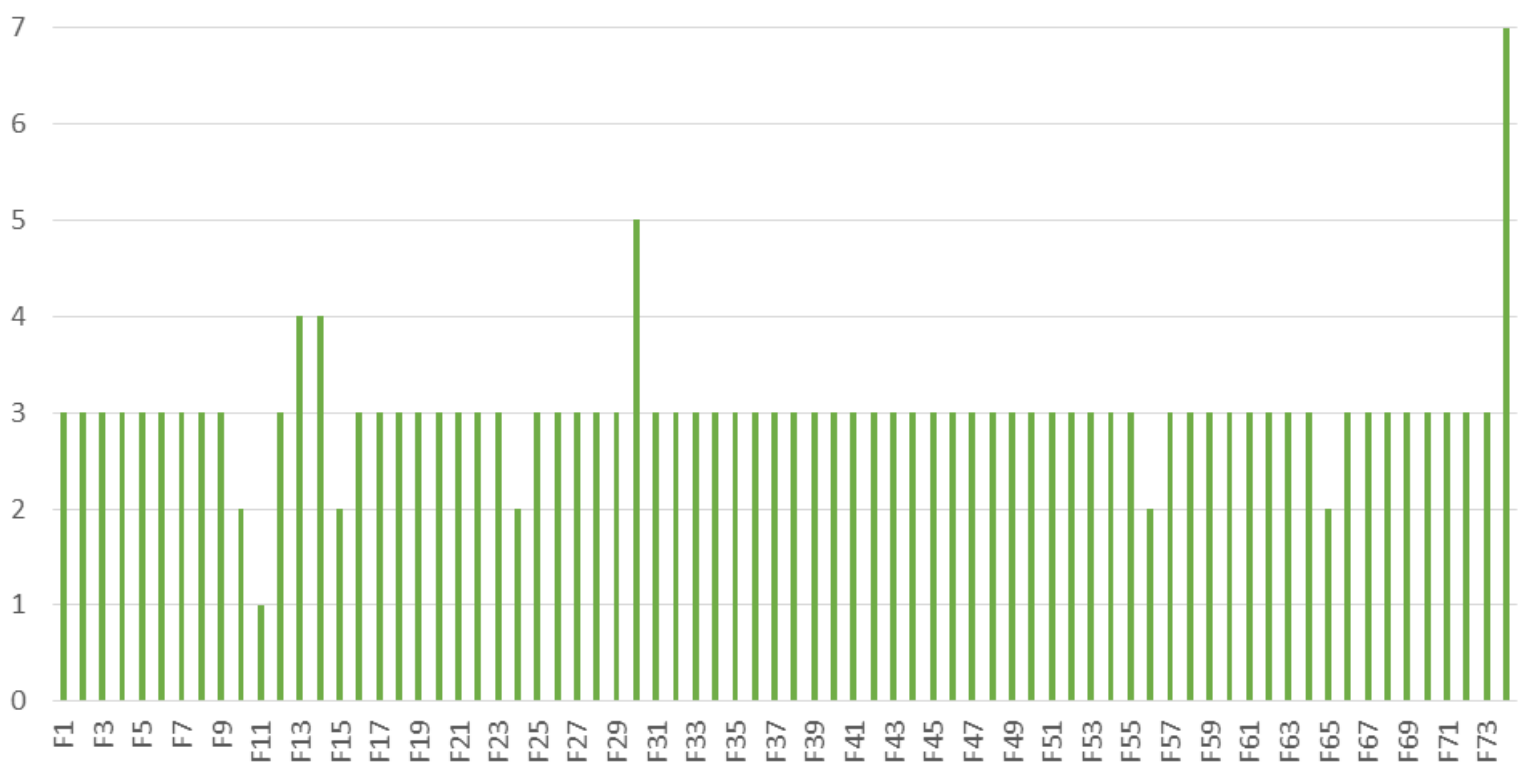

Fig. 1. Partial risk levels on risk factors

$$
\mathrm{N}_{\mathrm{rg}} \frac{\sum_{74}=1}{\sum R_{i} r_{i}}=\frac{1(7 \times 7)+0(6 \times 6)+1(5 \times 5)+2(4 \times 4)+64(3 \times 3)+5(2 \times 2)+1(1 \times 1)}{1 \times 7+0 \times 6+1 \times 5+2 \times 4+64 \times 3+5 \times 2+1 \times 1}=\frac{703}{223}=3,15
$$


Table 1. Proposed measures for workplace - driver

\begin{tabular}{|c|c|c|c|}
\hline \multirow{2}{*}{$\begin{array}{l}\text { No. } \\
\text { crt. }\end{array}$} & \multirow{2}{*}{ Risk factors } & \multirow{2}{*}{$\begin{array}{l}\text { Risk } \\
\text { level }\end{array}$} & Proposed measures \\
\hline & & & Nominalization of the measure \\
\hline $\mathbf{0}$ & 1 & 2 & 3 \\
\hline 1. & $\begin{array}{l}\text { Incorrect use of protective } \\
\text { equipment and other protective } \\
\text { equipment }\end{array}$ & 7 & $\begin{array}{l}\text { Organizational measures: } \\
\text { - equipping drivers with protective equipment } \\
\text { appropriate to the activity they carry out; } \\
\text { - instructing drivers about the consequences of } \\
\text { non-compliance with security restrictions. }\end{array}$ \\
\hline 2. & $\begin{array}{l}\text { Low level of nighttime lighting } \\
\text { - example: when driving at } \\
\text { night, there is a glare caused by } \\
\text { the incorrect use of lights by } \\
\text { other road users }\end{array}$ & 5 & $\begin{array}{l}\text { Technical measures: } \\
\text { - checking the condition of the lighting } \\
\text { installation on the truck before leaving the race } \\
\text { and leaving the darkness; } \\
\text { Organizational measures: } \\
\text { - performing regular medical check-ups at the } \\
\text { established deadlines; } \\
\text { - the formation of the travel routes according to } \\
\text { the driver's fatigue; } \\
\text { - transport as much as possible during the day. }\end{array}$ \\
\hline 3. & $\begin{array}{l}\text { Design of particles on the } \\
\text { windscreen when it breaks }\end{array}$ & 4 & $\begin{array}{l}\text { Organizational measures: } \\
\text { - observance of the regular distance from the car } \\
\text { that is moving forward; } \\
\text { - compliance with traffic rules. }\end{array}$ \\
\hline 4. & $\begin{array}{l}\text { Antifreeze flow when the } \\
\text { pressure hoses are broken }\end{array}$ & 4 & $\begin{array}{c}\text { Technical measures: } \\
\text { - checking the technical condition of the car at the } \\
\text { established deadlines; } \\
\text { Organizational measures: } \\
\text { - checking the pressure hose condition before } \\
\text { starting the machine; } \\
\text { - tracking the wear to the hose and immediately } \\
\text { replacing those that no longer meet the conditions } \\
\text { of use. }\end{array}$ \\
\hline
\end{tabular}

Note:

1. The implementation deadlines and the persons responsible for these measures will be established by the worker designated for safety and health at work together with the manager of the work place;

2. The measures proposed to eliminate or mitigate risk factors will be included in the provision and protection plan.

\section{Interpretation of workplace evaluation results: driver}

The level of global risk calculated for the workplace (driver) is equal to 3.15 , the value that is in the category of workplaces with an acceptable level of risk.

The result is supported by the "Evaluation Sheet", which shows that of the total of 74 identified risk factors (Figure 2), only 4 exceeded as a partial risk level the value of 3: one belonging to the category of maximum risk factors (7), one falling under high risk factors (5) and two in the category of medium risk factors (4).
To mitigate or eliminate the four risk factors, the measures outlined in the "Proposed Workplace Bill" are required for the workplace [3, 4].

Regarding the distribution of the risk factors on the generating sources, the situation is as follows (Figure 3):

- $33.78 \%$, factors of the car / work equipment;

- $14.86 \%$, factors of the working environment;

- $17.57 \%$, factors related to the work load;

- $33.78 \%$, contractor's factors.

From the "Evaluation Sheet" analysis, 71.62\% of identified risk factors can have irreversible consequences on the performer (DEATH or INVALIDITY). 
Table 2. The four risk factors that are unacceptable are:

\begin{tabular}{|c|c|c|c|}
\hline F74 & $\begin{array}{c}\text { Misapplication or misuse of E.I.P. and other means of } \\
\text { protection }\end{array}$ & N.V.P.R. & 7 \\
\hline F30 & $\begin{array}{c}\text { Low light level at work at night - example when driving at } \\
\text { night, is the phenomenon of blindness caused by the incorrect } \\
\text { use of lights by other road users }\end{array}$ & N.V.P.R. & 5 \\
\hline F13 & The design of particles on the windscreen when broken; & N.V.P.R. & 4 \\
\hline F14 & Antifreeze rupture when pressure hoses are broken; & N.V.P.R. & 4 \\
\hline
\end{tabular}

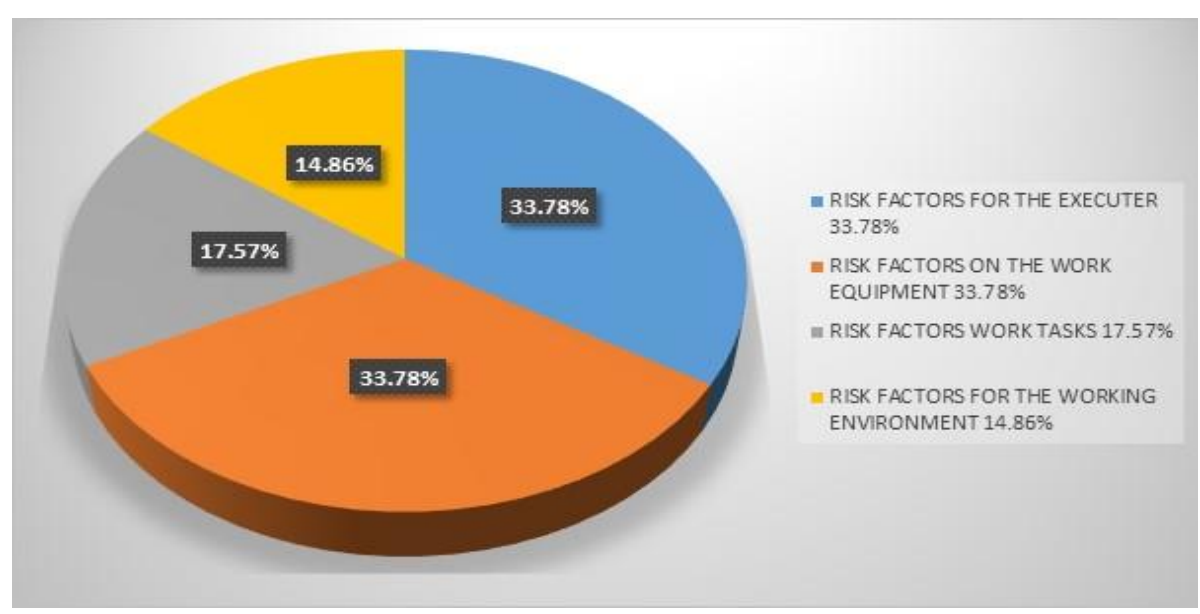

Fig. 2. Share of risk factors identified by the generating source within the work system

\section{Conclusion}

The calculation of the overall risk level resulted in a value of 3.15 , which means that driver has an acceptable risk. By analysing the partial risk level of the 74 risk factors, only four of them raised a higher risk, being unacceptable.

From the "Evaluation Sheet" analysis, 71.62\% of identified risk factors can have irreversible consequences on the performer (DEATH or INVALIDITY).

Why is workplace safety important? There is more to this question than one think.

Workplace safety is very important for each and every employee in the industry because all the workers desire to work in a safe and protected atmosphere. Health and safety are the key factor for all the industries in order to promote the wellness of both employees and employers. It is a duty and moral responsibility of the company to look after the employee's protection $[7,8]$.
Each and every person who leaves home for their work in the morning should come back home in good health in evening.

\section{References}

[1]. Alexandru Țiclea, Răspunderea disciplinară în raporturile de muncă, Editura CH Beck, București, 2017.

[2]. Alexandru Țiclea, Răspunderea pentru daune in raporturile de muncă, Editura Universul Juridic, București, 2014.

[3]. Alexa C., Transporturi şi expediţii internaţionale, București, Editura ALL, 1995.

[4]. Doina Banciu, Mihail Alexandrescu, Adrian Eşanu, Sisteme inteligente de Transport, ghid pentru utilizatori şi dezvoltatori, Editura Tehnică, Bucureşti, 2003.

[5]. Gheorghe Caraiani, Tratat de Transporturi vol. I şi II, Bucureşti, Editura Lumina Lex, 2001.

[6]. Gheorghe Filip, Roditis C., Filip L., Dreptul transporturilor, Casa de editură şi presă "Şansa", București, 1998.

[7]. Ioan Tătar, Dominic Petreanu, Andreea Câţu, Adrian Petreanu, Marin Lepădatu, Gabor Sandor, Dan Mărgărit, Răzvan Oprişan, Manualul operatorului de transport rutier, Editura IFPTR, Miercurea Ciuc, 2008.

[8]. Ion Jinga, Andrei Popescu, Integrarea Europeană. Dicţionar de termeni comunitari, Editura Lumina Lex, 2000. 